\title{
Research and Development of Unmanned Aviation Vehicle System for Disaster Countermeasures
}

\author{
Ikuo Yamamoto ${ }^{1,}$, Naohiro Inagawa ${ }^{2}$, Takunori Tsuji ${ }^{3}$, Takenari Otawa ${ }^{3}$, \\ Takashi Takimoto ${ }^{4}$, Masaaki Iwasaki ${ }^{5}$ and Tomokazu Hiratsuka ${ }^{5}$ \\ ${ }^{1}$ Nagasaki University, 1-14 Bunkyomachi, Nagasaki, Nagasaki 852-8521, Japan \\ ${ }^{2}$ Nippon Bunri University, 1727 Ichiki, Oita, Oita 870-0397, Japan \\ ${ }^{3}$ Logical Product Corporation, 2-25-5 Matoba, Minami-ku, Fukuoka, Fukuoka 811-1314, Japan \\ ${ }^{4}$ Kitakyushu National College of Technology, 5-20-1 Shii, Kokuraminami-ku, Kitakyushu, Fukuoka \\ 802-0985, Japan \\ ${ }^{5}$ BraTech Co.,Ltd., 1-8 Hibikino, Wakamatsu-ku, Kitakyushu, Fukuoka 808-0135 Japan \\ aiyamamoto2011@gmail.com
}

Keywords: Flying Observation Robot, Disk Type, Compact Boat Type, Balloon Type, GPS, LAN, Hazard Map, Mobile Phone.

\begin{abstract}
The authors developed low cost unmanned helicopter, real time video data transmitting system and new type flying robots. The effectiveness is confirmed by real field experiment tests. Hazard map for disaster countermeasures is made on the basis of data obtained by the aviation vehicle system. The hazard map is delivered directly to a smart phone and a tablet PC. Therefore residents can keep track of disaster information quickly and accurately.
\end{abstract}

\section{Introduction}

This research concerns the construction of a multifunctional observation and the forwarding system for disaster situation, as a prompt information transmission when the disaster occurred. Mainly, the development of the observation and the forwarding system is transferring the image information and sensor information by using usual Internet network. It means no using expensive special equipment. Moreover, it can offer a variety of observation forwarding systems that match to needs of the disaster area changing hour by hour, by combined with small flight systems which have separate special function. It proposes this as construction of the system design method. When disaster such as earthquake, typhoon, tsunami, etc happens, quick response to keep lifeline will be required [1][2], and electricity should especially be important. In conventional way, when a utility pole settled in mountain area or island area has damaged, for example, disaster area should be surveyed to check damage conditions through manned helicopter and so on. But it is very difficult to operate helicopter because of heavy weather condition such as strong wind and also difficult to keep low altitude. Then, instead manned helicopter, safer, more accurate, faster and lower cost method to correct information [3] of damaged area is required. The authors developed low cost unmanned helicopter and real time video data transmitting system [4][5]. We also had held field experiment on this system. Since the proposal system can perform unmanned observation, there is no risk for developing the second disaster. Even if the system should receive damage, it is small size and a low cost, so an observation risk can be reduced to the minimum.

\section{Construction of the System}

Summary of the system. The radio control helicopter was selected as an unmanned flying machine [6] for the new system. Although a radio control airplane [7], a balloon, a kite [8], etc. were examined, the radio control helicopter, which can keep stable flight [9] view with low cost, was found to be the best machine to correct information of the disaster area. The radio control helicopter is equipped semiautomatic control (feedback control based on displacement of the yaw angle which a gyroscope 

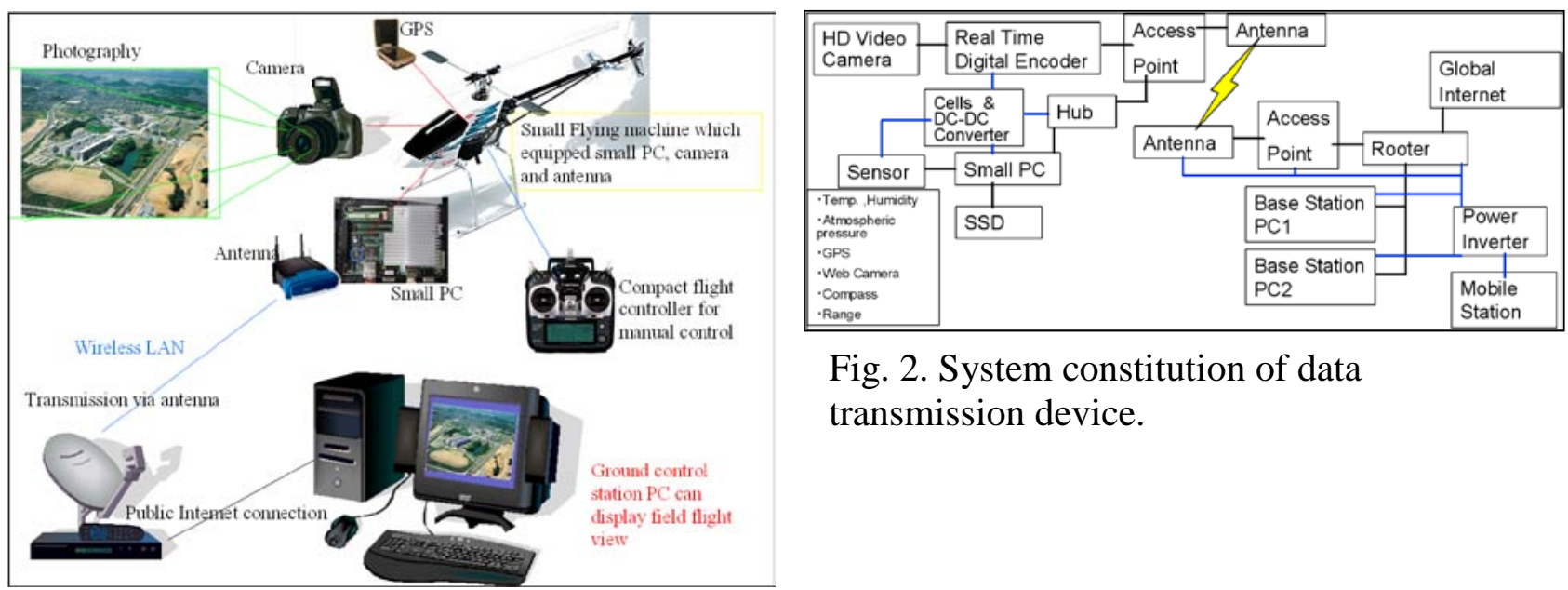

Fig. 2. System constitution of data transmission device.

Fig. 1. Summary of the system.

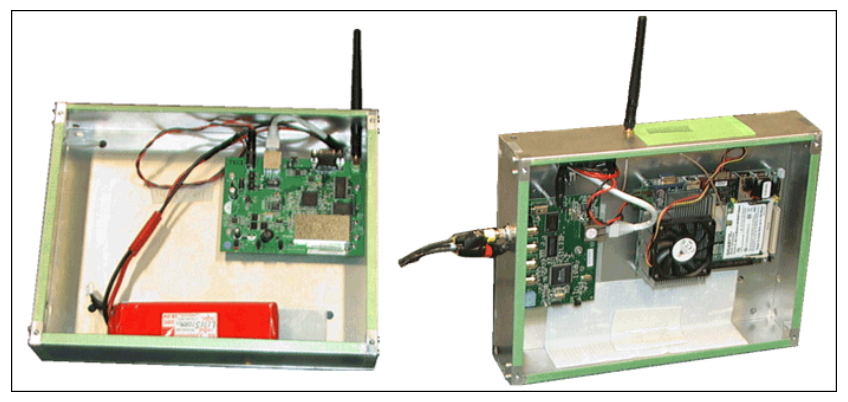

Fig. 3. Video data transmitting unit.

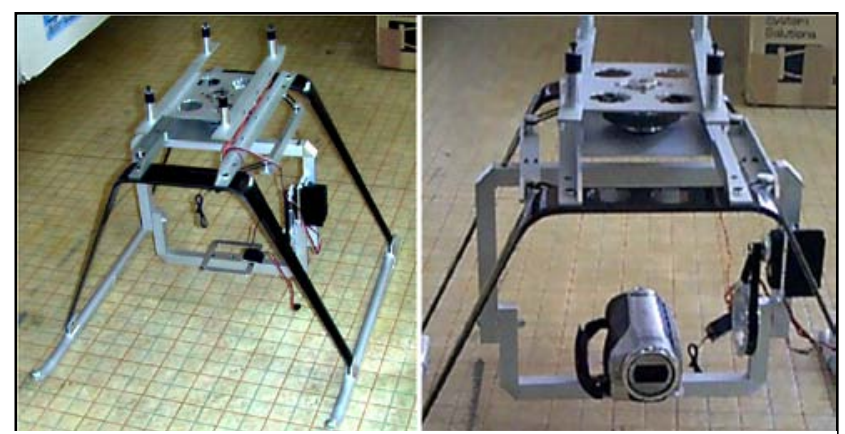

Fig. 4. Skid.

unit detects) of a rotation angle only. This helicopter is controlled by the expert, and the autonomous device [10] using by GPS is not installed. Authors also developed real time video data transmitting system through wireless LAN and equipped on the radio control helicopter. A summary of the system is shown in Fig. 1.

Design of video data transmitting system. The figure of system constitution for video data transmitting system is shown in Fig. 2. The video camera outputs an analog video signal while doing HD video recording. Next, this system encode analog video signal to digital internet video data and transmitting through wireless LAN. Here, authors equipped the small board PC in a design for the expansion observation such as temperature / humidity / altitude / the run trace. This PC was also connected to the wireless LAN, and all of the data from PC can be received with a video data on a base station. This system can show real time video images of disaster area to ground base station and distanced home PC monitor via public Internet connection. When the disaster spot is away from the base station, it shows an effect by using long distance specifications access point and added loop antenna for base station.

\section{Production of the Hardware}

Main body of copter. The specification is shown in Table 1 . There is a payload of about 3kg besides the main body of copter weight. It is necessary to produce video transmitting system weight within $3 \mathrm{~kg}$, and to equip it.

Production of video data transmitting unit. This unit consists of video data encoding device, small PC to observe (for extending), battery, transmitting device (wireless LAN) and 2 antennas. Because of the payload limit of the main body of the copter, video data transmitting unit was produced within 3kg. The battery, PC, and the video encoder arranged right and left balance thinking. The case was produced from $0.3 \mathrm{~mm}$ thickness aluminium board bending for lightening. Weight in this part is about $2 \mathrm{~kg}$. This unit is shown in Fig. 3. 
Table 1. Result of measurement.

\begin{tabular}{|l|l|}
\hline Full length & $1570[\mathrm{~mm}]$ \\
\hline Overall height & $670[\mathrm{~mm}]$ \\
\hline Weight & $6600[\mathrm{~g}]$ \\
\hline A payload & $3000[\mathrm{~g}]$ \\
\hline Flight hours & $30 \mathrm{~min}$. \\
\hline The gear ratio & $8: 1: 5.18$ \\
\hline Power source & 2 st. gasoline engine \\
\hline Displacement volume & $30[\mathrm{cc}]$ \\
\hline A tail drive type & Belt drive \\
\hline A mainframe & Duralumin Upper: $2[\mathrm{~mm}]$, Lower: $3[\mathrm{~mm}]$ \\
\hline
\end{tabular}

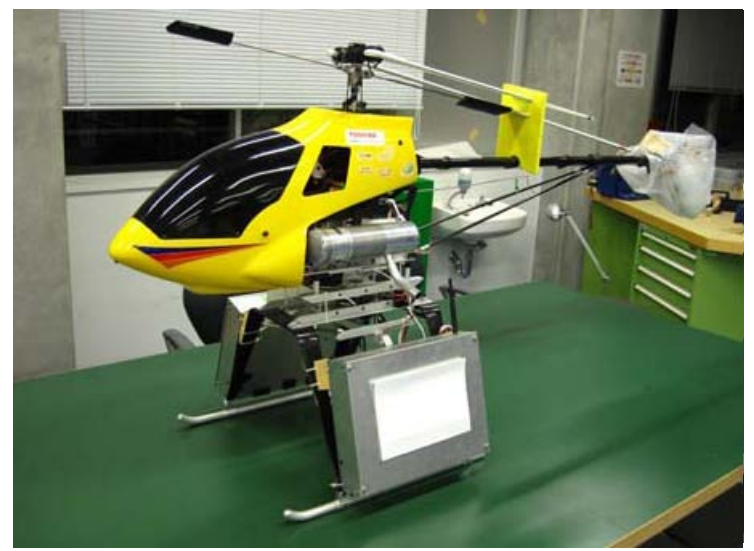

Fig. 5. Flying observation robot.

Equipping of a camera. The HD video camera is installed for Full HD (1920 x 1080 pixels) recording and analogue video signal (640 x 480 pixels) output. The camera is fixed to the skid (camera movable plinth). Fig. 4 shows the skid.

Equipping of video data transmitting unit. The final assembly, video data transmitting unit was equipped beside the skid. The copter photograph assembled as observation robot is shown in Fig. 5.

Installation of base station. The base station set it up in the car for the movement operation. The power supply is AC $100 \mathrm{v}$ converted from DC 12v battery of the car. Fig. 6 shows the base station that set it up.

\section{Operation Experiment}

Operation experiment A. The operation experiment of this system was done in the airport (Soeda-cho, Fukuoka Prefecture) for the model aircraft in March, 2008. Fig. 7 shows the appearance of the experiment. As a result of the experiment, it succeeded in real-time transmitting of the video image through the wireless Internet standard. The transmitting distance between copter and base station was about $100 \mathrm{~m}$. The quality of transmitted video image was excellent $(640 \mathrm{x} 480$ pixels, 30fps, Delay: about 0.5sec).

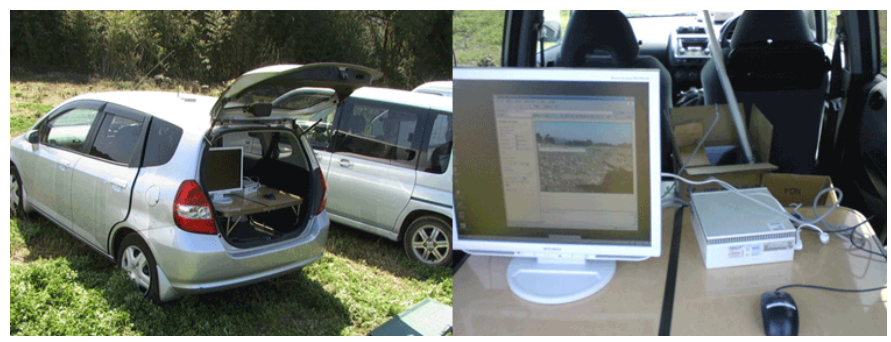

Fig. 6. Base station.

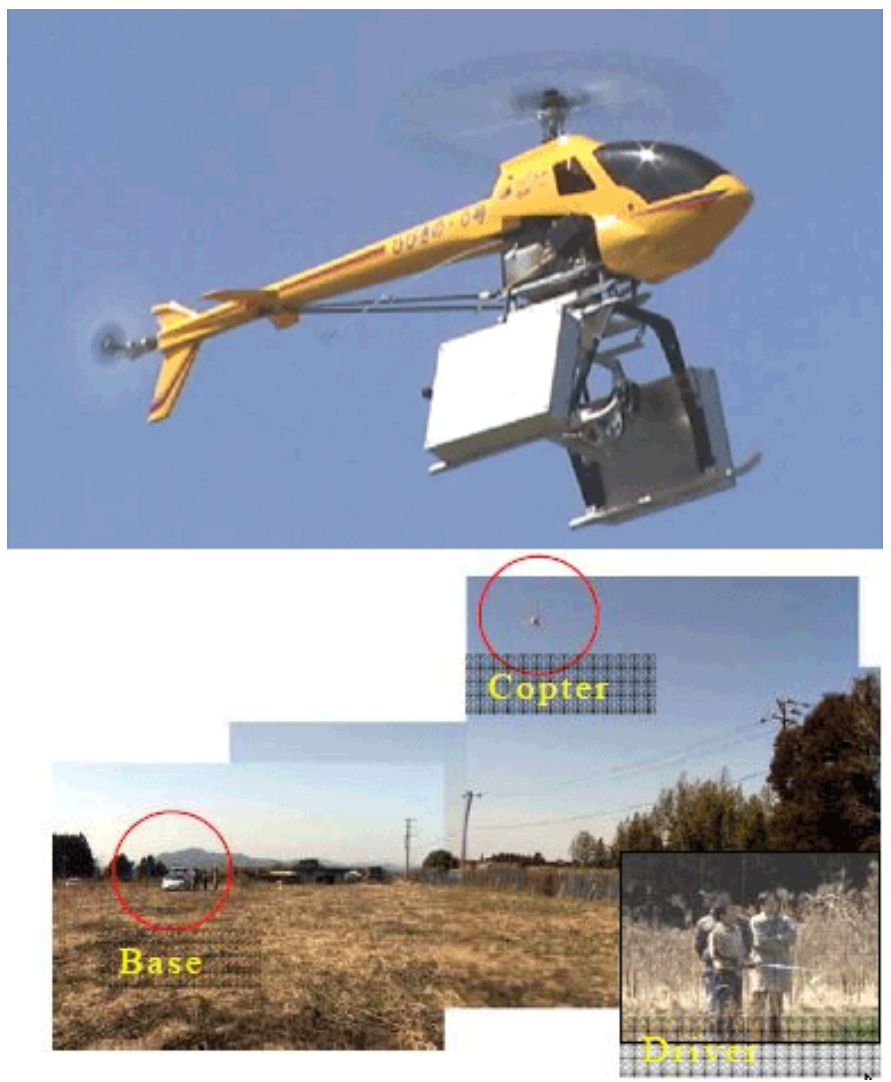

Fig. 7. Appearance of experiment. 


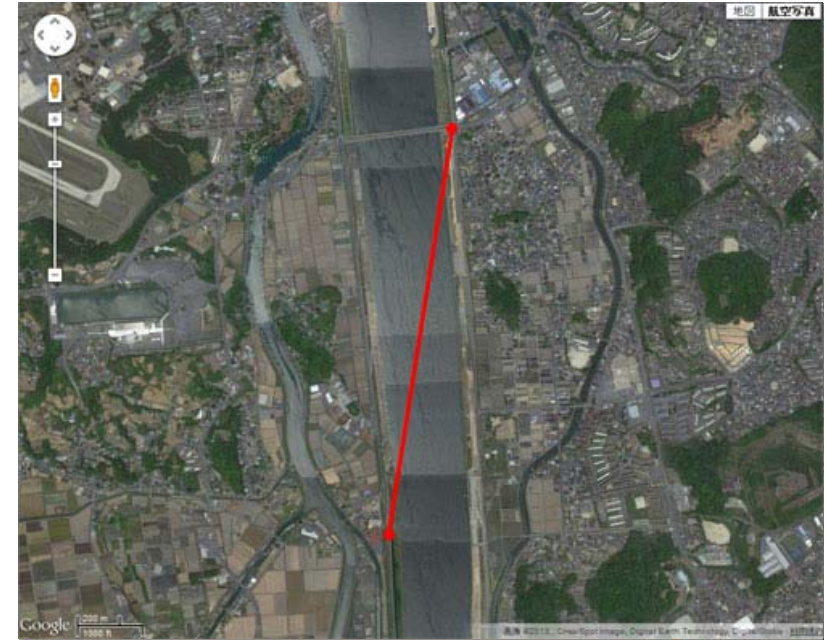

Fig. 8. Measurement of distance transmitting video data.

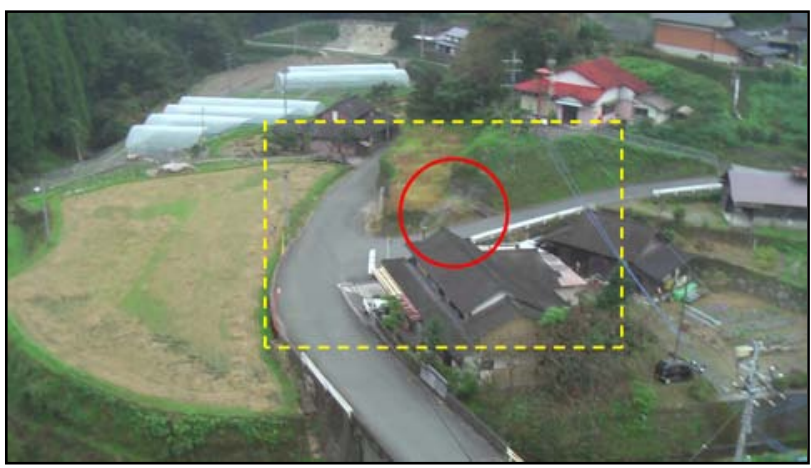

Fig. 10. Appearance of the experiment (easy control position).

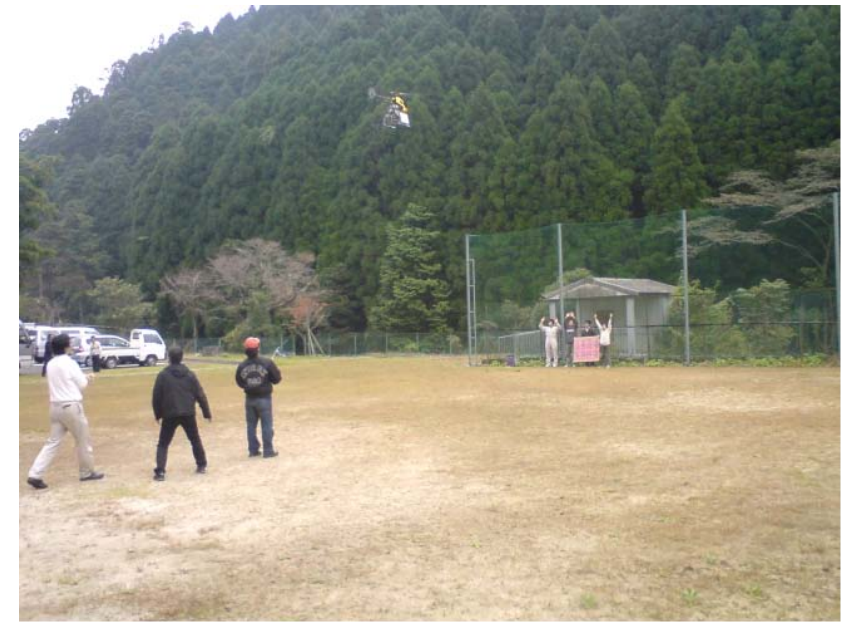

Fig. 9. Appearance of the experiment (easy control position).

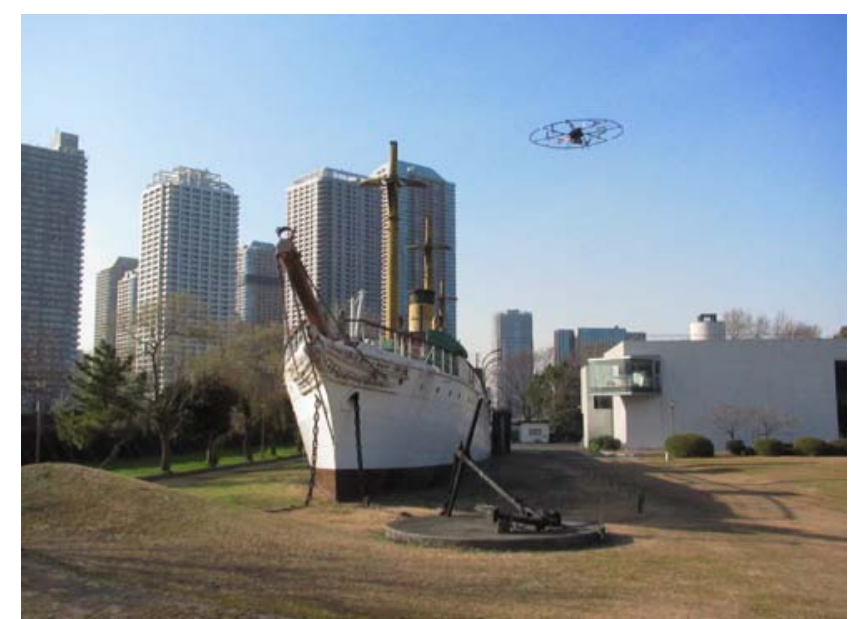

Fig. 11. Disk type flying robot.

Exploratory experiment. It had experimented to investigate the limit of transmitting distance before operation experiment B. Fig. 8 shows the result. In the experiment, the video data transmitting unit was detached from the body of copter. The limit distance to keep an excellent real time video image was $1.5 \mathrm{~km}$ in the sight distance.

Operation experiment B. The authors participated in the experiment on the surveillance study for Kyushu Bureau of Telecommunications Ministry of Internal Affairs and Communications in October, 2008. Experimental location was Joyo-cho, Yame City, Fukuoka Prefecture. This region is a mountainous district where the influence of the natural damage (road cutting by the earth and sand fallen dawn tree etc.) is frequently received, and an inconvenient region far from the urban area. It was confirmed to be able to transmit video data via internet in like a disaster area. Fig. 9 shows the appearance of the experiment at this time. Fig. 10 shows the picture from HD video data recorded on flying copter. By Fig. 10, it was possible to take a picture of the smoke of cooking from the sky. Therefore, it seems that the forest fire can surely be found.

\section{Disk Type Flying Robot}

The authors want to equip it with infrared camera to operate at night. Moreover, the authors have developed a new type flying robot. Because, the current robot is difficult to operate and to move easy control position as shown in Fig. 9 and Fig. 10.

It is a disk type flying robot and has eight brushless motors (Fig. 11, 12). Its weight (time equipped with the camera) is about $2 \mathrm{~kg}$ and also its maximum payload is about $2 \mathrm{~kg}$. Flight time is about 15 minutes. It doesn't hit the rotor directly even if knocking against by any chance because the rotor 


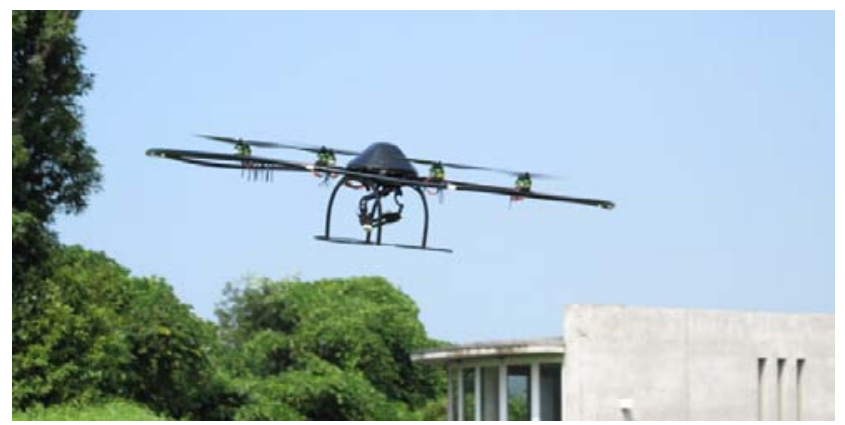

Fig. 12. Appearance of the experiment (easy control position).

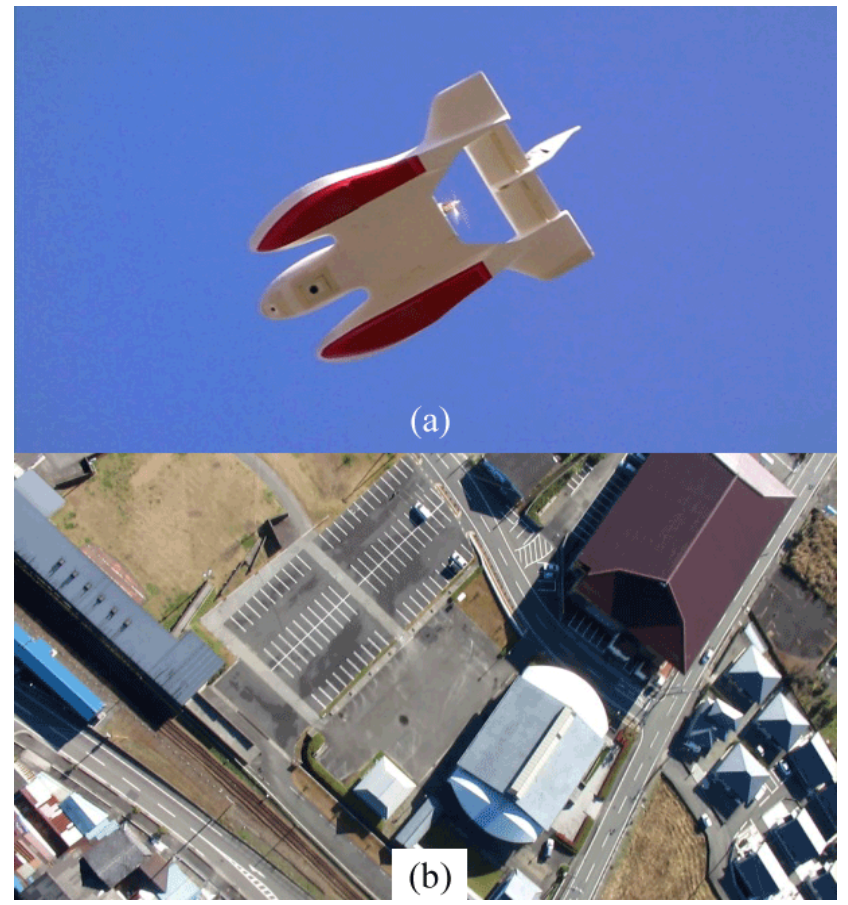

Fig. 14. Verification experiments. (a) a compact flying boat robot in sky, (b) The picture from the compact flying boat robot.

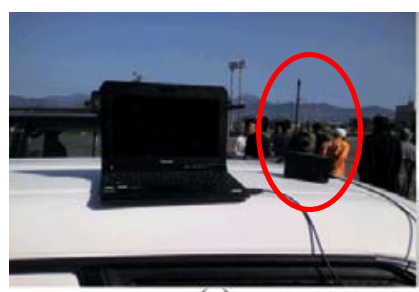

(a)

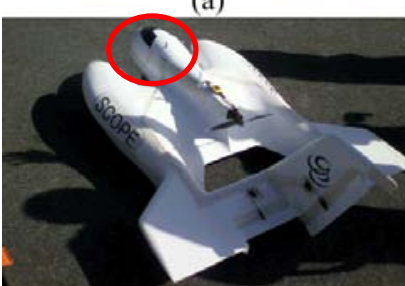

(c)

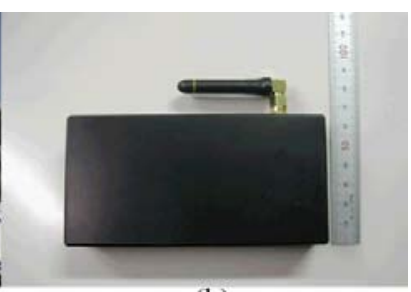

(b)

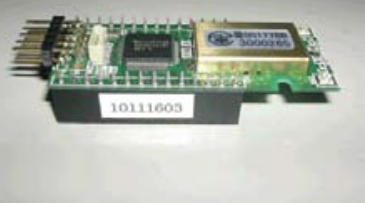

(d)

Fig. 13. Wireless Transfer Unit. (a) a base unit, (b) a handset unit, (c) an antenna of handset unit, (d) a wireless module (950MHz).

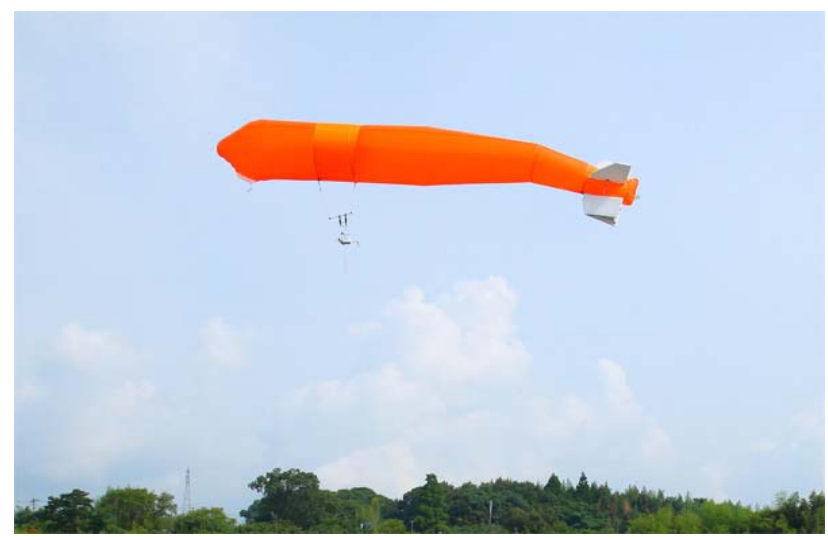

Fig. 15. Balloon type flying robot.

outside is a disk shape (Original structure). Compared with the copter used by the operation experiment, this feature is small, cheap and flight stability. The shape of the new type which was flight stability developed after the experiment of making to visible of the current of air generated when flying was conducted.

\section{Compact Flying Boat Robot}

The authors altered a compact flying boat robot to mount observation equipments (ex. camera, various sensors), and conducted experiments. A specified low power wireless transfer unit was developed with a view to mount the robot. This wireless transfer unit runs in 950MHz band. Fig. 13 shows the wireless transfer unit.

The authors were conducted verification experiments for the compact flying boat robot which is mounted the new wireless transfer unit. Fig. 14 shows the verification experiments.

Maneuverability and stability. The compact flying boat robot which is mounted the new wireless transfer unit took off from tight spot, and landed on tight spot. In addition, the robot stably made flights and monitored video picture on the ground in real time. The optimization of the direction of the camera is an issue in the future. 
Table 2. Result of measurement.

\begin{tabular}{|l|c|c|}
\hline & $\begin{array}{c}\text { packet arrival rate } \\
(\%)\end{array}$ & $\begin{array}{c}\text { radio field strength } \\
(\mathrm{dBm})\end{array}$ \\
\hline Before takeoff & $100 \%$ & -67 \\
\hline low altitude & $86 \%$ & -90 \\
\hline high altitude 1 & $88 \%$ & -92 \\
\hline high altitude 2 & $80 \%$ & -93 \\
\hline high altitude (farness) & $70 \%$ & -94 \\
\hline After landing & $99 \%$ & -80 \\
\hline
\end{tabular}

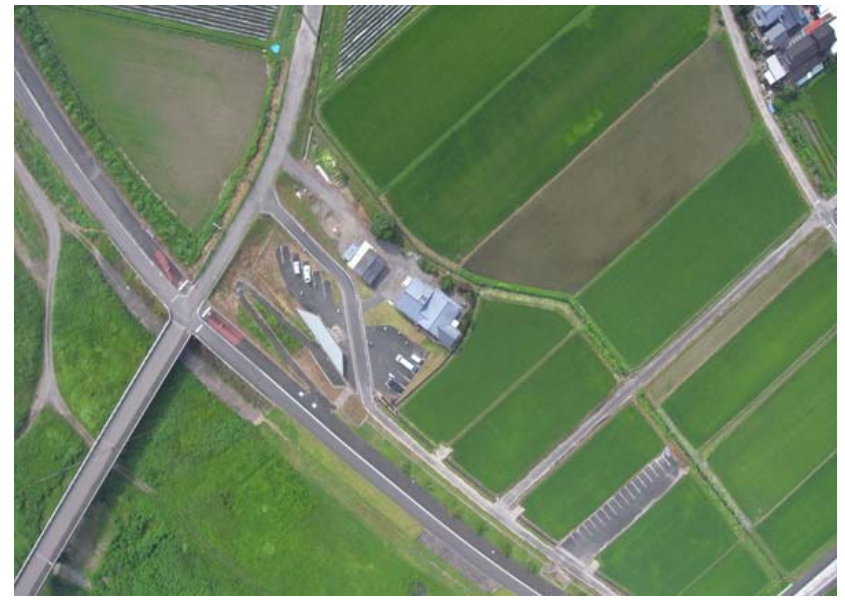

(a)

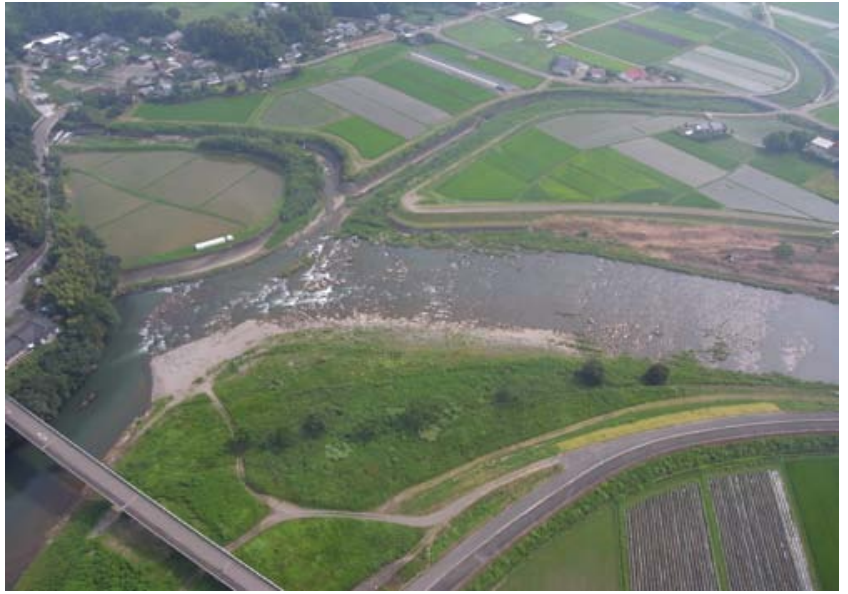

(b)

Fig. 16. The picture from the balloon type flying robot. (a) Private home and farming area, (b) River.

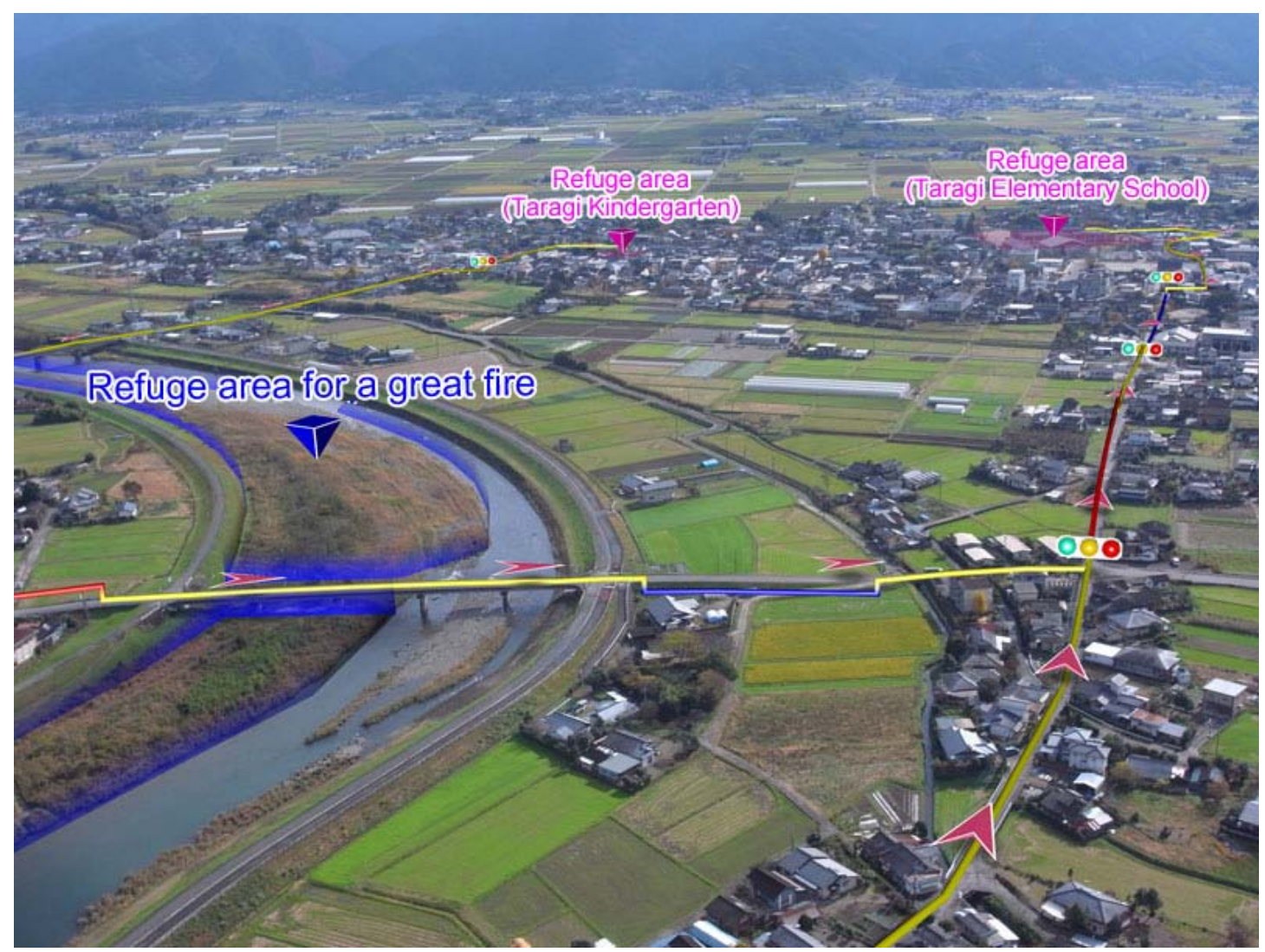

Fig. 17. Example of the map of evacuation routes 


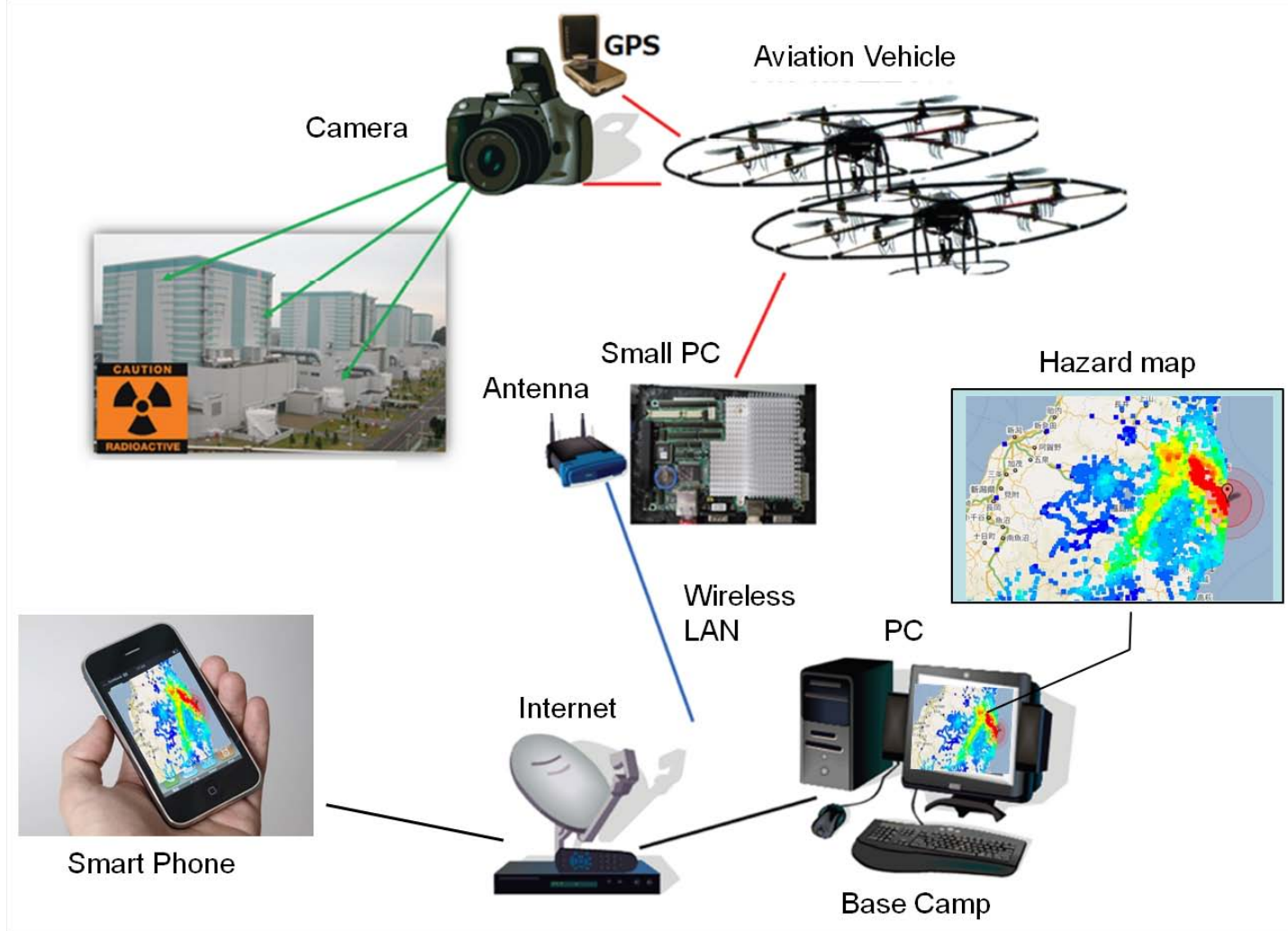

Fig. 18. the unmanned aviation vehicle system for disaster countermeasures with the hazard map.

Capability and packet arrival rate. The authors measured the packet arrival rate by measurement software which was developed by the authors. Table 2 shows the results of measurement. An implementation of re-forwarding communication protocol and an efficiency of the antenna are issues in the future.

\section{Balloon Type Flying Robot}

The balloon type (Fig. 15) is our new type unmanned flying observation robot. Fig. 16 shows the result of verification experiments. The authors are presently verifying practical effectiveness of the balloon type flying robot for the disaster observation.

\section{Hazard Map System}

Hazard map for disaster countermeasures is made on the basis of data obtained by the aviation vehicle system. The Fig. 17 shows the example of the map of evacuation routes. The hazard map is delivered directly to a smart phone and a tablet PC. Therefore residents can keep track of disaster information quickly and accurately. The Fig. 18 shows the unmanned aviation vehicle system for disaster countermeasures with the hazard map.

\section{Conclusions}

The wireless control copter was produced, and its payload was $3 \mathrm{~kg}$, the height of flight experiment was about $30 \mathrm{~m}$, and it is confirmed the observation robot which can flight in the wind speed of 10 $\mathrm{m} / \mathrm{sec}$. Flight time is about 20 minutes. The authors have succeeded the development of system which can transfer real-time video image via Internet at the same time HD Video camera recording. Video image quality of a real-time transmitting is $640 \times 480$ pixels, 30 frame/sec, about 0.5 sec delay. Fig. 19 shows the real time monitoring display of the system. The system can measure the levels of radiation and the amount of CO2 in the sky. 


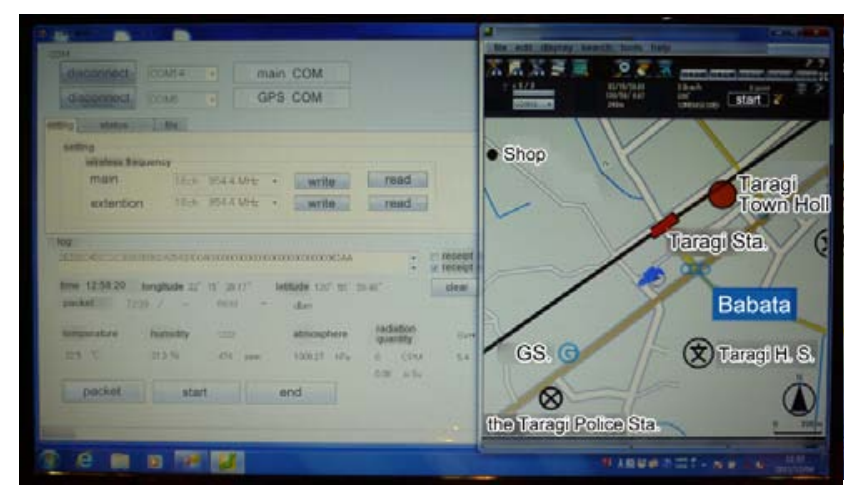

Fig. 19. Real time monitoring display.

Furthermore, in the demonstration experiments of the disk type flying robot, the compact flying boat robot and the balloon type flying robot, the authors had positive outcomes. In the future, the authors will advance the development of these robots to solve the issues which are become clear by the demonstration experiments.

Hazard map for disaster countermeasures is made on the basis of data obtained by the aviation vehicle system. The hazard map is delivered directly to a smart phone and a tablet

PC. Therefore residents can keep track of disaster information quickly and accurately.

The authors will apply the developed system to the disaster area by the earthquake and typhoon in the near future.

\section{Acknowledgment}

This work was supported by SCOPE, Ministry of Internal Affairs and Communications of Japan.

\section{References}

[1] Groeve, T. D., et al., Near Real Time Flood Alerting for the Global Disaster Alert and Coordination System Joint Research Centre of the European Commission, Proceedings ISCRAM2007, (2007) 33-39.

[2] Nagatani, K., et al., Development of a Networked Robotic System for Disaster Mitigation -System Description of Multi-robot System and Performance Tests of the Robots-, Springer Tracts in Advanced Robotics, 42 (2008) 453-462.

[3] Ahmed, A., et al., UAV Based Monitoring System and Object Detection Technique Development for a Disaster Area, The International Archives of the Photogrammetry, Remote Sensing and Spatial Information Sciences, xxxvii (partB8), (2008) 373-378

[4] Yamamoto, I., et al., Research on network system of unmanned flying observation robot, Proceedings of the 27th Annual Conference of Kyushu Chapter of the Society of Instrument and Control Engineers, 103B6 (2008) 195-196.

[5] Inagawa, N., et al., Research on network system of unmanned flying observation robot, Proceedings of ICROS-SICE International Joint Conference, Fukuoka International Congress Center, Japan, (2009) 2644-2647.

[6] Nonami, K., et al., Prospect and Recent Research \& Development for Civil Use Autonomous Unmanned Aircraft as UAV and MAV, Journal of System Design and Dynamics, Special Issue on New Trends of Motion and Vibration Control, 1 (2) (2007) 120-128.

[7] William, E., et al., An Aerial Robot Prototype for Situational Awareness in Closed Quarters, Proceedings of the IEEE International Conference on Intelligent Robots and Systems, Las Vegas,Nevada,October, (2007) 61-66.

[8] Paul, Y., et al., A Kite and Teleoperated Vision System for Acquiring Aerial Images, Proceedings of the IEEE International Conference on Robotics \& Automation, Taipei, Taiwan, September 14-19, (2003) 1404-1409.

[9] Musial, M., et al., Development of a Flight Control Algorithm for the Autonomously Flying Robot MARVIN, Proceedings of International Workshop Advanced Robotics and its Applications 2000, (2000) 44-48.

[10] Naruoka, M., et al., A Powerful Autopilot System for Small UAVs with Accurate INS/GPS Integrated Navigation, Proceedings of JSASS-KSAS Joint International Symposium on Aerospace Engineering, Kitakyushu, JAPAN, Paper 005 (2007). 